\title{
sciendo
}

\section{Radiolytic synthesis of gold nanoparticles in HEMA-based hydrogels: Potentialities for imaging nanocomposites}

\begin{abstract}
This article reports on the radiolytic synthesis of nanocomposites containing gold nanoparticles (AuNPs) within two types of hydrogels based on 2-hydroxyethyl methacrylate (HEMA): (i) plain networks with various contents in ethylene glycol dimethacrylate (EGDMA), as a cross-linker and (ii) stimuli-responsive (SR) networks prepared from these monomers copolymerized with [2-(methacryloyloxy)ethyl]trimethylammonium chloride (MADQUAT) to confer $\mathrm{pH}$-switchable swelling. Hydrogels were prepared by photopolymerization with well-defined composition and a high degree of monomer conversion using two experimental procedures, as xerogels or in aqueous solution. Besides MADQUAT, acrylic acid (AA) or $N$-isopropylacrylamide have been tested as copolymers, yielding $\mathrm{pH}$ - or temperature-sensitive hydrogels, respectively. Isothermal swelling in water was affected by monomer composition. Electron beam (EB) irradiation at doses up to $100 \mathrm{kGy}$ of poly(HEMA) xerogels and water-swollen networks prepared with $0.5 \mathrm{wt} \%$ of EGDMA had a moderate impact on swelling characteristics and thermomechanical properties of the plain materials, whereas small amounts of extractables were formed. Poly(HEMA)-based nanocomposites containing AuNPs were successfully obtained by EB irradiation of samples swollen by aqueous solutions of $\mathrm{Au}(\mathrm{III})$. The effects of dose and cross-linking density on the formation of AuNPs were monitored by UV-visible spectroscopy. Irradiation at well-defined temperatures of the $\mathrm{Au}(\mathrm{III})$-loaded SR hydrogels induced the formation of nanoparticles with size-dependent features, whereas the efficiency of $\mathrm{Au}$ (III) reduction at $10 \mathrm{kGy}$ was not significantly affected by the network structure. EB-induced reduction of $\mathrm{Au}$ (III) in poly(HEMA) hydrogels using a lead mask to generate well-defined patterns yielded coloured and long-lasting images in the zones where the nanocomposite was formed.
\end{abstract}

Keywords: Functional hydrogels • Gold nanoparticles • Nanocomposites • Network properties • Radiation-induced reactions $\bullet$ Stimuli-responsiveness

\section{K. Dziarabina}

Université de Reims Champagne-Ardenne

Institut de Chimie Moléculaire de Reims

CNRS UMR 7312, BP 1039, 51687 Reims Cedex 2, France

and Lodz University of Technology

Faculty of Chemistry

Institute of Applied Radiation Chemistry

Wroblewskiego 15 Str., 93-590, Lodz, Poland

\section{U. Pinaeva, X. Coqueret}

Université de Reims Champagne-Ardenne

Institut de Chimie Moléculaire de Reims

CNRS UMR 7312, BP 1039, 51687 Reims Cedex 2, France

E-mail: xavier.coqueret@univ-reims.fr

S. Kadłubowski, P. Ulański ${ }^{\bowtie}$

Lodz University of Technology

Faculty of Chemistry

Institute of Applied Radiation Chemistry

Wroblewskiego 15 Str., 93-590, Lodz, Poland

E-mail: piotr.ulanski@p.lodz.pl

Received: 19 January 2021

Accepted: 22 February 2021

\section{Introduction}

As a part of a project aiming at patterning nanocomposites in hydrogels by radiation-mediated reduction of $\mathrm{Au}(\mathrm{III})$ ions into gold nanoparticles (AuNPs), we are currently investigating the synthesis of well-defined poly(HEMA)-based networks and evaluating the potentialities of radiation treatments for creating well-resolved and stable patterns made of AuNPs embedded in hydrogel matrices.

Since the early reports on the structural features and unique properties of metal nanoparticles (NPs) [1-3], various synthetic methods and experimental conditions have been reported in the literature to generate metal clusters starting from metal salts as precursors. Among them, chemical $[4,5]$ and photochemical [6] redox reactions have been successfully employed, while other highly efficient treatments based on sonication [7] or radiolytic reduction [8-10] have also been developed as greener alternatives. Compared to conventional chemical synthesis, the radiation-induced technique does not

0029-5922 @ 2021 The Author(s). Published by the Institute of Nuclear Chemistry and Technology.

This is an open access article under the CC BY-NC-ND 4.0 licence (http://creativecommons.org/licences/by-nc-nd/4.0/). 
require the use of any reducing agents. Moreover, by adjusting the dose rate, the radiation-induced method provides fine control over the growing rate of metal cluster, which enables therefore to tailor the properties of the reduced nanoparticles because of specific applications.

The radiolytic synthesis is particularly suitable for the generation of metal NPs in aqueous media via the generation of solvated electrons $\left(\mathrm{e}_{\mathrm{aq}}^{-}\right)$and hydrogen atoms $\left(\mathrm{H}^{\circ}\right)$, which can easily reduce metal ions such as, for instance, $\mathrm{Au}$ (III), down to zero-valent state [11]. The presence of polymeric solutes may induce a more complex reduction mechanism involving short- and long-lived polymeric species $[12,13]$. Nevertheless, the nanocomposite materials consisting of polymer hydrogel network and metallic NPs provide a synergetic effect to the complex material by reducing the risk of nanoparticle aggregation and at the same time enhancing the mechanical strength of the hydrogels. Furthermore, similarly to colloid solutions, the hydrogels containing metal NPs can play the role of reactors catalyzing chemical reactions taking place in aqueous solutions.

Several approaches in polymer/metal NPs synthesis are distinguished. Metal NPs, often functionalized to ensure good solubility in organic media and prevent aggregation, can be directly added to a monomer blend and further converted into a nanocomposite [14] or physically incorporated within an already prepared polymer matrix ("breathing in") [15]. This method, however, is likely to result in an inhomogeneous distribution of NPs. In situ chemical metal salt reduction is intended to overcome this issue. For example, Wang et al. [16] synthesized a hydrogel made of poly ( $N$-isopropylacrylamide) and co-monomers containing thiol groups that may form complexes with $\mathrm{Au}(\mathrm{III})$ ions, permitting therefore the formation of uniformly distributed stable and un-aggregated colloidal AuNPs upon addition of sodium borohydride (reducing agent). Alternatively, the radiolytic in situ route allows not only size-controllable and uniform nanoparticle generation due to the formation of reducing species with high reduction potentials but also avoids using any undesired chemicals, making the synthesis easier, cleaner, and more versatile. In this approach, the metal salt is either present in a monomer blend so that the metal ion reduction takes place simultaneously with the polymer matrix formation upon irradiation, or added to the pre-formed polymer matrix and then radiolytically processed. Thus, Marić et al. [17] reported a one-step synthesis of poly (ethylene oxide) (PEO)/ AuNPs nanocomposite hydrogels by $\gamma$-irradiation. Authors demonstrated that upon irradiation at $50 \mathrm{kGy}$ and alkaline $\mathrm{pH}$, the hydrogel nanocomposites were produced by simultaneous cross-linking of $\mathrm{PEO}$ chains and reduction of $\mathrm{Au}(\mathrm{III})$. In the second case, a prepared polymer matrix is allowed to swell in an aqueous metal salt solution before irradiation.

Among the various metal ions that can be reduced in the form of zero-valent nanoparticles, $\mathrm{Ag}(\mathrm{I})$ and $\mathrm{Au}(\mathrm{III})$ are of the greatest interest due to their nonlinear optical and catalytic properties [18-20]. Despite many successful studies on the radiolytic formation of AuNPs in aqueous media with $[9,21]$ and without [22] stabilizing agents such as, for instance, natural polysaccharide chitosan, there are much fewer reports on radiation-mediated metal nanoparticle formation within a hydrogel matrix available. Zhu et al. [23] obtained composite poly(NIPAm) hydrogels containing gold nanoparticles by gamma-irradiation-induced polymerization of NIPAm in the presence of gold precursor. Initiation by gamma rays has also been used by Marić $e t$ al. [17] who obtained hydrogels containing AuNPs by simultaneous cross-linking of PEO and reduction of $\mathrm{Au}$ (III) in an aqueous solution. The authors stressed the influence of $\mathrm{pH}$ on the character of the final product, concerning both the size of AuNPs and the character of the polymer matrix (continuous hydrogel vs. suspension). A similar approach has been recently applied for synthesizing AuNP/ poly (vinyl alcohol) (PVA) gels [24, 25]. Kumar et al. [26] have synthesized PVA-AgNPs hydrogel composites by $\gamma$-irradiation. It was demonstrated by viscosity measurements that $\mathrm{Ag}(\mathrm{I})$ reduction and PVA cross-linking were not taking place simultaneously upon radiolysis, and a complete metal salt reduction $\left(0.2 \mathrm{mM} \mathrm{AgNO}_{3}\right)$ was achieved at $3.3 \mathrm{kGy}$ resulting in $20 \mathrm{~nm}$ AgNPs. PVA was found to be a very efficient stabilizer to prevent aggregation of the resulted Ag clusters. Henríquez et al. [27] reported on in situ AgNPs embedded into photopolymerized hydroxyethyl methacrylate (HEMA)-based hydrogels with biocide properties. Krklješ et al. [28, 29] synthesized AgNP-containing hydrogels based on PVA. The composites were prepared by swelling the cross-linked polymer with $\mathrm{AgNO}_{3}$ aqueous solutions following $\gamma$-irradiation at $14 \mathrm{kGy} \cdot \mathrm{h}^{-1}$ dose rate, complete reduction of $\mathrm{Ag}(\mathrm{I})$ being achieved at $8 \mathrm{kGy}$ $(4 \mathrm{mM} \mathrm{AgNO} 3)$. Later on, the same group reported the poly ( $\mathrm{N}$-vinyl-2-pyrrolidone) (PVP)-AgNPs hydrogel nanocomposite preparation [30]. It was shown that PVP-AgNPs nanocomposites exhibited higher values of equilibrium swelling degree, Young's modulus, and molar mass between cross-links, while lower values of the diffusion coefficient and effective cross-link density were obtained, as compared to the pure PVP. Likewise, poly(HEMA) reported herein has excellent transparency, bio-compatibility (used in tissue engineering scaffolds, controlled drug delivery systems, wound dressings, etc.) and it has been originally used as a copolymer in contact lenses manufacturing providing suitable support for both optical and biomedical devices. Furthermore, copolymerization with MADQUAT, a monomer conferring thermally responsive solution properties to HEMA-based polymers and subsequent conversion of the hydrogel into a nanocomposite containing AuNPs has been evaluated for remote-controlled drug delivery based on hydrogel collapse at temperatures above lower critical solution temperature (LCST) resulting in a burst release of drugs.

This note reports on preliminary results on the radiolytic synthesis of gold nanocomposites within two types of hydrogels based on HEMA: (i) plain poly(HEMA) networks with various contents in ethylene glycol dimethacrylate (EGDMA) as a cross- 
-linker and (ii) stimuli-responsive (SR) networks prepared from the same monomers copolymerized with [2-(methacryloyloxy) ethyl] trimethylammonium chloride (MADQUAT), which is expected to impart a pH-dependent behaviour to the resulting copolymer network. These approaches require an advanced control of chemical modifications at the different stages of the elaboration process.

The synthesis of the host matrices was achieved by photopolymerization using UV radiation, a versatile method that allows for the rapid formation of hydrogel materials in various dimensions and shapes. We have also shown that, besides the gels mentioned above, other poly(HEMA)-based stimuli-sensitive gels can be easily obtained by this approach, including $\mathrm{pH}$-sensitive gels containing acrylic acid (AA) and temperature-sensitive gels containing $N$-isopropylacrylamide (NIPAm).

The obtained poly(HEMA)-based materials were characterized to assess the properties of the hydrogels, in the as-prepared state, after purification, and after EB-irradiation under various conditions. Attention was particularly paid to isothermal swelling in aqueous media.

In-situ formation of AuNPs was achieved by radiation-induced reduction of $\mathrm{Au}(\mathrm{III})$ ions present in the liquid phase of the hydrogels. UV-visible spectroscopy was selected as a simple and quite informative means for measuring the extent of the reductive process and for assessing some features of the formed nanoparticles. Preliminary tests were performed to evaluate the relevance of this method to pattern and to fix nanocomposite images in the depth of the hydrogel substrates.

\section{Experimental}

\section{Chemicals}

2-Hydroxyethyl methacrylate (97\%), EGDMA (98\%), 2-hydroxy-2-methylpropiophenone (>96\%), 2-hydroxy-2-methyl-1-phenyl-1-propanone (Darocur 1173), hydrogen tetrachloroaurate trihydrate (99.99\%), 2-(MADQUAT (75\% aqueous solution), and $N$-isopropylacrylamide $(\geq 99 \%)$ were purchased from Merck-Sigma-Aldrich, while AA (98\%) was supplied by Acros Organics. The monomers were used as received. 2-Propanol (99.6\%) was provided by VWR (Poland) and hydrogen peroxide (30\% in water) by Chempur (Poland). Aqueous solutions and swelling media were prepared using double distilled water.

\section{Synthesis of poly(HEMA) xerogels}

The polymerization of HEMA monomer with EGDMA as cross-linker and Darocur 1173 as photoinitiator was performed in bulk. Approximately $1.5 \mathrm{~g}$ of a precursor mixture based on HEMA, EGDMA, and Darocur 1173 (99.0 wt\%, $0.5 \mathrm{wt} \%$ and $0.5 \mathrm{wt} \%$, respectively, which correspond to $8.192 \mathrm{M}$ for methacrylate functions and $0.033 \mathrm{M}$ for the photoinitiator) was poured into a poly (tetrafluoroethylene) (PTFE) mold and exposed in air to the fluorescent tubes emitting at $365 \mathrm{~nm}$ for $15 \mathrm{~min}$ with an irradiance of $6 \mathrm{~mW} \cdot \mathrm{cm}^{-2}$ (UV Biolink, Vilber-Lourmat). The surface of the cured poly(HEMA) disks was washed with isopropanol, the disk samples were dried to constant weight in an oven at $60^{\circ} \mathrm{C}$, and finally polished to obtain a uniform thickness of $1.0 \pm 0.05 \mathrm{~mm}$.

\section{Synthesis of neat and stimuli-sensitive hydrogels based on poly (HEMA) in aqueous solutions}

In this procedure, cross-linking polymerization was performed in concentrated aqueous solutions of monomers containing hydrogen peroxide as a co-initiator. Gels based on pure poly(HEMA) have been synthesized at a constant ratio of HEMA to EGDMA equal 99:1 (v/v); this solution has been mixed with $30 \%$ aqueous solutions of $\mathrm{H}_{2} \mathrm{O}_{2}$ at volume ratios of $1: 1,2: 1,3: 1$, and $4: 1$. After homogenization, $1 \mathrm{ml}$ of the final solution has been poured into the PTFE mold, resulting in a liquid layer thickness of $2 \mathrm{~mm}$, and exposed to the air to $254 \mathrm{~nm}$ photon beam with an irradiance of $2.6 \mathrm{~mW} \cdot \mathrm{cm}^{-2}$ (CL-1000 Ultraviolet Crosslinker, UVP) at total exposure doses up to $22 \mathrm{~J} \cdot \mathrm{cm}^{-2}$.

Gels containing MADQUAT have been synthesized by UV irradiation (as above, exposure dose kept constant at $8 \mathrm{~J} \cdot \mathrm{cm}^{-2}$ ) of solutions containing $50 \mathrm{vol} . \%$ of aqueous $30 \% \mathrm{H}_{2} \mathrm{O}_{2}, 45-48.75 \mathrm{vol} . \%$ of HEMA/EGDMA (99:1) solution, and 1.25-5 vol.\% of aqueous $75 \%$ MADQUAT, with no pH adjustment. Gels containing AA or $N$-isopropylacrylamide (NIPAm) have been synthesized by the same method, using solutions containing from 1.25 vol.\% to 5 vol.\% AA or NIPAm. Molar compositions of all samples used for synthesizing hydrogels in aqueous systems are shown in Tables 1-4.

For swelling tests of MADQUAT- or AA-containing gels, $\mathrm{pH}$ was adjusted with $1 \mathrm{M}$ solutions of $\mathrm{NaOH}$ or $\mathrm{HCl}$, and swelling was performed at room temperature (RT). Swelling tests of NIPAm-containing gels have been performed in water (no $\mathrm{pH}$ adjustment), in beakers placed in a temperature-controlled bath.

\section{Electron beam irradiation and in situ synthesis of AuNPs}

Irradiation of the poly(HEMA)-based materials was performed with a $10 \mathrm{MeV}$ Linac at an average dose rate of about $3 \mathrm{kGy} \cdot \mathrm{s}^{-1}$ (IONISOS, Chaumesnil, France). The treatment was fractionated in $5 \mathrm{kGy}-$ -passes for doses up to $20 \mathrm{kGy}$, and in $25 \mathrm{kGy}$-passes for doses from $25 \mathrm{kGy}$ to $100 \mathrm{kGy}$. Poly(HEMA) samples in water-swollen or dry states were sealed in plastic bags with a minimum amount of air and submitted to EB-irradiation at doses up to $100 \mathrm{kGy}$. Radiolytic synthesis of poly(HEMA)-AuNPs composites was performed on poly(HEMA) disks swollen with $\mathrm{Au}$ (III) aqueous solution. The samples sealed in plastic bags with a minimum amount of air and kept 
Table 1. Gelation dose $\left(D_{g}\right)$ and probability ratio of chain breakage to cross-linking $\left(p_{0} / q_{0}\right)$ for hydrogels based on HEMA/EGDMA with the addition of a different amount of $\mathrm{H}_{2} \mathrm{O}_{2}(30 \%$ aqueous solution) synthesized by UV irradiation $\left(254 \mathrm{~nm}\right.$, irradiance $\left.2.6 \mathrm{~mW} \cdot \mathrm{cm}^{-2}\right)$

\begin{tabular}{|c|c|c|c|c|}
\hline $\begin{array}{l}\text { Sample } \\
\text { make-up }\end{array}$ & $\begin{array}{c}\text { HEMA/EGDMA } \\
(99 / 1): 50 \text { vol. } \% \\
30 \% \mathrm{H}_{2} \mathrm{O}_{2}: 50 \text { vol. } \%\end{array}$ & $\begin{array}{c}\text { HEMA/EGDMA } \\
(99 / 1): 67 \text { vol. } \% \\
30 \% \mathrm{H}_{2} \mathrm{O}_{2}: 33 \text { vol. } \%\end{array}$ & $\begin{array}{c}\text { HEMA/EGDMA } \\
(99 / 1): 75 \text { vol. } \% \\
30 \% \mathrm{H}_{2} \mathrm{O}_{2}: 25 \text { vol. } \%\end{array}$ & $\begin{array}{c}\text { HEMA/EGDMA } \\
(99 / 1): 80 \text { vol. } \% \\
30 \% \mathrm{H}_{2} \mathrm{O}_{2}: 20 \text { vol. } \%\end{array}$ \\
\hline $\begin{array}{l}\text { Sample } \\
\text { composition }\end{array}$ & $\begin{array}{c}\text { methacrylate functions } \\
4.123 \mathrm{~mol} \cdot \mathrm{L}^{-1} \\
\mathrm{H}_{2} \mathrm{O}_{2} 4.895 \mathrm{~mol} \cdot \mathrm{L}^{-1}\end{array}$ & $\begin{array}{c}\text { methacrylate functions } \\
5.497 \mathrm{~mol} \cdot \mathrm{L}^{-1} \\
\mathrm{H}_{2} \mathrm{O}_{2} 3.263 \mathrm{~mol} \cdot \mathrm{L}^{-1}\end{array}$ & $\begin{array}{c}\text { methacrylate functions } \\
6.184 \mathrm{~mol} \cdot \mathrm{L}^{-1} \\
\mathrm{H}_{2} \mathrm{O}_{2} 2.448 \mathrm{~mol} \cdot \mathrm{L}^{-1}\end{array}$ & $\begin{array}{c}\text { methacrylate functions } \\
6.596 \mathrm{~mol} \cdot \mathrm{L}^{-1} \\
\mathrm{H}_{2} \mathrm{O}_{2} 1.958 \mathrm{~mol} \cdot \mathrm{L}^{-1}\end{array}$ \\
\hline $\begin{array}{l}D_{g}\left(\mathrm{~J} \cdot \mathrm{cm}^{-2}\right) \\
p_{0} / q_{0}\end{array}$ & $\begin{array}{c}2.33 \\
0\end{array}$ & $\begin{array}{c}2.55 \\
0\end{array}$ & $\begin{array}{c}2.92 \\
0\end{array}$ & $\begin{array}{l}3.55 \\
0.25\end{array}$ \\
\hline
\end{tabular}

Table 2. Gel fractions for hydrogels based on HEMA/EGDMA/ $\mathrm{H}_{2} \mathrm{O}_{2}(30 \%$ aqueous solution) with various amounts of MADQUAT ( $75 \%$ aqueous solution), synthesized by UV irradiation $\left(254 \mathrm{~nm}\right.$, irradiance $2.6 \mathrm{~mW} \cdot \mathrm{cm}^{-2}$, total exposure dose $8 \mathrm{~J} \cdot \mathrm{cm}^{-2}$

\begin{tabular}{|c|c|c|c|c|}
\hline $\begin{array}{c}\text { Sample } \\
\text { make-up }\end{array}$ & $\begin{array}{c}\text { HEMA/EGDMA } \\
\text { (99/1): } 50 \text { vol. } \% \\
30 \% \mathrm{H}_{2} \mathrm{O}_{2}: 50 \text { vol. } \%\end{array}$ & $\begin{array}{c}\text { HEMA/EGDMA } \\
\text { (99/1): } 48.75 \text { vol. } \% \\
\text { MADQUAT } 1.25 \text { vol. } \% \\
30 \% \mathrm{H}_{2} \mathrm{O}_{2}: 50 \text { vol. } \%\end{array}$ & $\begin{array}{l}\text { HEMA/EGDMA } \\
\text { (99/1): } 47.5 \text { vol. } \% \\
\text { MADQUAT } 2.5 . \% \\
30 \% \mathrm{H}_{2} \mathrm{O}_{2}: 50 \text { vol. } \%\end{array}$ & $\begin{array}{c}\text { HEMA/EGDMA } \\
\text { (99/1): } 45 \text { vol. } \% \\
\text { MADQUAT } 5 \text { vol. } \% \\
30 \% \mathrm{H}_{2} \mathrm{O}_{2}: 50 \text { vol. } \%\end{array}$ \\
\hline $\begin{array}{l}\text { Sample } \\
\text { composition }\end{array}$ & $\begin{array}{c}\text { methacrylate functions } \\
4.123 \mathrm{~mol} \cdot \mathrm{L}^{-1} \\
\mathrm{H}_{2} \mathrm{O}_{2} 4.895 \mathrm{~mol} \cdot \mathrm{L}^{-1}\end{array}$ & $\begin{array}{l}\text { methacrylate functions } \\
4.020 \mathrm{~mol} \cdot \mathrm{L}^{-1} \\
\text { MADQUAT } 0.049 \mathrm{~mol} \cdot \mathrm{L}^{-1} \\
\mathrm{H}_{2} \mathrm{O}_{2} 4.895 \mathrm{~mol} \cdot \mathrm{L}^{-1}\end{array}$ & $\begin{array}{c}\text { methacrylate functions } \\
3.917 \mathrm{~mol} \cdot \mathrm{L}^{-1} \\
\text { MADQUAT } 0.097 \mathrm{~mol} \cdot \mathrm{L}^{-1} \\
\mathrm{H}_{2} \mathrm{O}_{2} 4.895 \mathrm{~mol} \cdot \mathrm{L}^{-1}\end{array}$ & $\begin{array}{c}\text { methacrylate functions } \\
\text { 3.710 } \mathrm{mol} \cdot \mathrm{L}^{-1} \\
\text { MADQUAT } 0.194 \mathrm{~mol} \cdot \mathrm{L}^{-1} \\
\mathrm{H}_{2} \mathrm{O}_{2} 4.895 \mathrm{~mol} \cdot \mathrm{L}^{-1}\end{array}$ \\
\hline $\begin{array}{l}\text { Gel fraction } \\
(\%)\end{array}$ & 82.0 & 75.1 & 65.3 & 50.9 \\
\hline
\end{tabular}

Table 3. Gel fractions for hydrogels based on HEMA/EGDMA/ $\mathrm{H}_{2} \mathrm{O}_{2}$ (30\% aqueous solution) with various amounts of AA, synthesized by UV irradiation $\left(254 \mathrm{~nm}\right.$, irradiance $2.6 \mathrm{~mW} \cdot \mathrm{cm}^{-2}$, total exposure dose $\left.8 \mathrm{~J} \cdot \mathrm{cm}^{-2}\right)$

\begin{tabular}{|c|c|c|c|c|}
\hline $\begin{array}{l}\text { Sample } \\
\text { make-up }\end{array}$ & $\begin{array}{c}\text { HEMA/EGDMA } \\
(99 / 1): 50 \text { vol. } \% \\
30 \% \mathrm{H}_{2} \mathrm{O}_{2}: 50 \text { vol. } \%\end{array}$ & $\begin{array}{c}\text { HEMA/EGDMA } \\
\text { (99/1): } 48.75 \text { vol. } \% \\
\text { AA: } 1.25 \text { vol. } \% \\
30 \% \mathrm{H}_{2} \mathrm{O}_{2}: 50 \text { vol. } \%\end{array}$ & $\begin{array}{c}\text { HEMA/EGDMA } \\
\text { (99/1): } 47.5 \text { vol. } \% \\
\text { AA: } 2.5 \text { vol. } \% \\
30 \% \mathrm{H}_{2} \mathrm{O}_{2}: 50 \text { vol. } \%\end{array}$ & $\begin{array}{c}\text { HEMA/EGDMA } \\
\text { (99/1): } 45 \text { vol. } \% \\
\text { AA: } 5 \text { vol. } \% \\
\text { 30\% } \mathrm{H}_{2} \mathrm{O}_{2}: 50 \text { vol. } \%\end{array}$ \\
\hline $\begin{array}{l}\text { Sample } \\
\text { composition }\end{array}$ & $\begin{array}{c}\text { methacrylate functions } \\
4.123 \mathrm{~mol} \cdot \mathrm{L}^{-1} \\
\mathrm{H}_{2} \mathrm{O}_{2} 4.895 \mathrm{~mol} \cdot \mathrm{L}^{-1}\end{array}$ & $\begin{array}{c}\text { methacrylate functions } \\
4.020 \mathrm{~mol} \cdot \mathrm{L}^{-1} \\
\text { AA } 0.182 \mathrm{~mol} \cdot \mathrm{L}^{-1} \\
\mathrm{H}_{2} \mathrm{O}_{2} 4.895 \mathrm{~mol} \cdot \mathrm{L}^{-1}\end{array}$ & $\begin{array}{c}\text { methacrylate functions } \\
3.917 \mathrm{~mol} \cdot \mathrm{L}^{-1} \\
\text { AA } 0.364 \mathrm{~mol} \cdot \mathrm{L}^{-1} \\
\mathrm{H}_{2} \mathrm{O}_{2} 4.895 \mathrm{~mol} \cdot \mathrm{L}^{-1}\end{array}$ & $\begin{array}{c}\text { methacrylate functions } \\
3.710 \mathrm{~mol} \cdot \mathrm{L}^{-1} \\
\text { AA } 0.729 \mathrm{~mol} \cdot \mathrm{L}^{-1} \\
\mathrm{H}_{2} \mathrm{O}_{2} 4.895 \mathrm{~mol} \cdot \mathrm{L}^{-1}\end{array}$ \\
\hline $\begin{array}{l}\text { Gel fraction } \\
(\%)\end{array}$ & 82.0 & 92.2 & 90.9 & 88.3 \\
\hline
\end{tabular}

Table 4. Gel fractions for hydrogels based on HEMA/EGDMA/ $\mathrm{H}_{2} \mathrm{O}_{2}(30 \%$ aqueous solution) with various amounts of $N$-isopropylacrylamide, synthesized by UV irradiation $\left(254 \mathrm{~nm}\right.$, irradiance $2.6 \mathrm{~mW} \cdot \mathrm{cm}^{-2}$, total exposure dose $\left.8 \mathrm{~J} \cdot \mathrm{cm}^{-2}\right)$

\begin{tabular}{|c|c|c|c|c|}
\hline $\begin{array}{l}\text { Sample } \\
\text { make-up }\end{array}$ & $\begin{array}{c}\text { HEMA/EGDMA } \\
\text { (99/1): } 50 \text { vol. } \% \\
\text { 30\% } \mathrm{H}_{2} \mathrm{O}_{2}: 50 \text { vol. } \%\end{array}$ & $\begin{array}{l}\text { HEMA/EGDMA } \\
\text { (99/1): } 48.75 \text { vol. } \% \\
\text { NIPAm: } 1.25 \mathrm{wt} \% \\
30 \% \mathrm{H}_{2} \mathrm{O}_{2}: 50 \text { vol. } \%\end{array}$ & $\begin{array}{l}\text { HEMA/EGDMA } \\
\text { (99/1): } 47.5 \text { vol. } \% \\
\text { NIPAm: } 2.5 \text { wt } \% \\
\text { 30\% } \mathrm{H}_{2} \mathrm{O}_{2}: 50 \text { vol. } \%\end{array}$ & $\begin{array}{c}\text { HEMA/EGDMA } \\
\text { (99/1): } 45 \text { vol. } \% \\
\text { NIPAm: } 5 \text { wt } \% \\
30 \% \mathrm{H}_{2} \mathrm{O}_{2}: 50 \text { vol. } \%\end{array}$ \\
\hline $\begin{array}{l}\text { Sample } \\
\text { composition }\end{array}$ & $\begin{array}{c}\text { methacrylate functions } \\
4.123 \mathrm{~mol} \cdot \mathrm{L}^{-1} \\
\mathrm{H}_{2} \mathrm{O}_{2} 4.895 \mathrm{~mol} \cdot \mathrm{L}^{-1}\end{array}$ & $\begin{array}{c}\text { methacrylate functions } \\
4.020 \mathrm{~mol} \cdot \mathrm{L}^{-1} \\
\text { NIPAm } 0.110 \mathrm{~mol} \cdot \mathrm{L}^{-1} \\
\mathrm{H}_{2} \mathrm{O}_{2} 4.895 \mathrm{~mol} \cdot \mathrm{L}^{-1}\end{array}$ & $\begin{array}{c}\text { methacrylate functions } \\
3.917 \mathrm{~mol} \cdot \mathrm{L}^{-1} \\
\text { NIPAm } 0.221 \mathrm{~mol} \cdot \mathrm{L}^{-1} \\
\mathrm{H}_{2} \mathrm{O}_{2} 4.895 \mathrm{~mol} \cdot \mathrm{L}^{-1}\end{array}$ & $\begin{array}{c}\text { methacrylate functions } \\
\text { 3.710 mol } \cdot \mathrm{L}^{-1} \\
\text { NIPAm } 0.442 \mathrm{~mol} \cdot \mathrm{L}^{-1} \\
\mathrm{H}_{2} \mathrm{O}_{2} 4.895 \mathrm{~mol} \cdot \mathrm{L}^{-1}\end{array}$ \\
\hline $\begin{array}{l}\text { Gel fraction } \\
(\%)\end{array}$ & 82.0 & 75.8 & 70.3 & 65.7 \\
\hline
\end{tabular}

in the dark before being submitted to EB-irradiation at doses from $5 \mathrm{kGy}$ to $25 \mathrm{kGy}$.

Synthesis of AuNPs in the poly(HEMA-co-MADQUAT) hydrogels has been performed by swelling gel samples (synthesized as described above and pre-swollen in water for two weeks) in freshly made aqueous $1 \mathrm{mM} \mathrm{Au(III)} \mathrm{solution} \mathrm{at} \mathrm{pH} 2$ or $\mathrm{pH} 7$ for $2 \mathrm{~h}$, and subsequent immediate irradiation by $6 \mathrm{MeV}$ electron beam (EB) generated by Elektronika ELU-6e linear accelerator (pulsed beam, $20 \mathrm{~Hz}, 4 \mu \mathrm{s}$ pulse duration, the average dose rate of $63 \mathrm{~Gy} \cdot \mathrm{s}^{-1}$ as determined by polymer film dosimetry - B3WIN- 


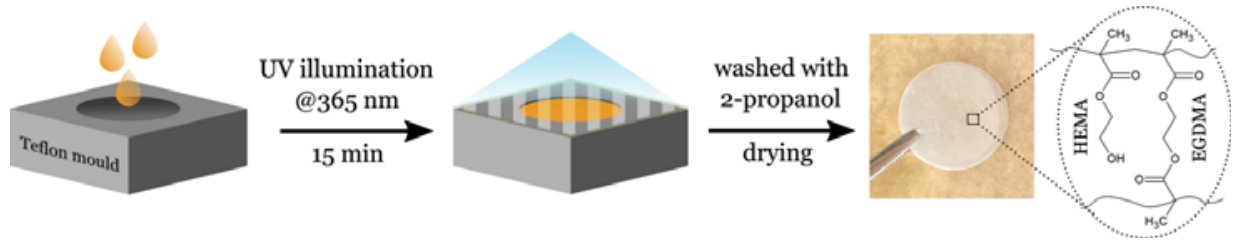

Scheme 1. Scheme of the poly(HEMA) xerogel synthesis by photopolymerization.

-Dose Dosimeters by GEX Corporation USA) at a total dose of $1 \mathrm{kGy}, 2 \mathrm{kGy}$, and $5 \mathrm{kGy}$, in closed but not sealed Petri dishes.

\section{Swelling measurements}

Structural changes occurring in poly(HEMA) networks upon exposure to EB were evaluated by swelling measurements. The swollen hydrogels were removed from flasks filled with double distilled water at regular time intervals, blotted with a clean paper towel, weighed, and replaced in the same soaking water bath. The swelling measurements were continued until a constant weight was reached for each sample. All measurements were made in duplicate. The equilibrium degree of swelling $\left(\mathrm{DS}_{\mathrm{eq}}\right)$ was calculated from the difference in weight between the disk's weight in the equilibrium swollen state $w_{\text {eq }}$ at $30^{\circ} \mathrm{C}$ and as material dried to constant weight $w_{0}$, using Eq. (1).

$$
\mathrm{DS}=\frac{w_{\mathrm{eq}}-w_{0}}{w_{0}}
$$

The final weight loss from the extractables after EB irradiation was estimated using Eq. (2),

$$
\text { weight loss }(\%)=\frac{w_{0}-w_{i r r}}{w_{0}} \times 100 \%
$$

where $w_{0}$ is the initial weight of dry disk before irradiation, $w_{i r}$ is the weight of the irradiated disk (in the swollen or dried state), swollen to extract possible scission fragments and dried to constant weight.

Alternatively, the degree to which the monomer and cross-linker have been polymerized and incorporated into the covalent network can be expressed as the gel fraction (Eq. (3)).

$$
\text { gel fraction }(\%)=100 \%-\text { weight loss }(\%)
$$

\section{Spectroscopic and thermomechanical analysis (DMA) of poly(HEMA) materials}

DMA measurement was performed on non-irradiated and EB-treated $1 \mathrm{~mm}$-thick poly(HEMA) bars to measure the viscoelastic response using a Q800 DMA rheometer (TA Instruments) at $1 \mathrm{~Hz}$ frequency and $15 \mu \mathrm{m}$ amplitude in the temperature interval from $30^{\circ} \mathrm{C}$ to $180^{\circ} \mathrm{C}$.

The spectroscopic properties of polished poly(HEMA) substrates and nanocomposites were recorded in the UV-vis domain (transmission mode, from $200 \mathrm{~nm}$ to $800 \mathrm{~nm}$ ) with an Agilent Cary 50 instrument (Agilent Technologies, Santa Clara, CA, USA).

\section{Results and discussion}

Photochemical synthesis of PHEMA-based xerogels

Free radical polymerization of blends including HEMA as the main monomer (99.5, 99.4, 99.0, 98.5 or $94.5 \mathrm{wt} \%)$, EGDMA as a cross-linking agent (0, $0.1,0.5,1$ or $5 \mathrm{wt} \%$ ), and Darocur 1173 as the photoinitiator $(0.5 \mathrm{wt} \%)$ was carried out upon exposure to $365 \mathrm{~nm}$ resulting in the formation of cross-linked hydrophilic networks as illustrated in Scheme 1.

The choice of the photoinitiator and its concentration in the blend has been made in such a way that the incident beam $365 \mathrm{~nm}$ penetrates deeply into the $1.5 \mathrm{~mm}$ thick samples, due to the low absorption coefficient of the photoinitiator's $n-\pi^{*}$ transition. Simple calculations showed that under these experimental conditions the gradient of energy absorption between the top and bottom surfaces of the sample is very limited [24].

\section{FTIR monitoring}

To monitor the progress of HEMA polymerization, Fourier-transform infrared spectroscopy (FTIR) measurements were performed on 2 mm-thick samples of HEMA/EGDMA/Darocur 1173 (99/0.5/0.5 wt $\%$ ) precursor mixture cured by exposure to the $365 \mathrm{~nm}$ source for cumulated time intervals. As seen from Fig. 1, the near IR band at $6168 \mathrm{~cm}^{-1}$, corresponding to the third harmonic wavenumber of the methacrylate $\mathrm{C}=\mathrm{C}$ double bond stretching mode, is gradually decreasing as the exposure to UV illumination increases from $0 \mathrm{~min}$ to $60 \mathrm{~min}$.

Kinetic profiles representing the progress of methacrylate polymerization in monomer blends con-

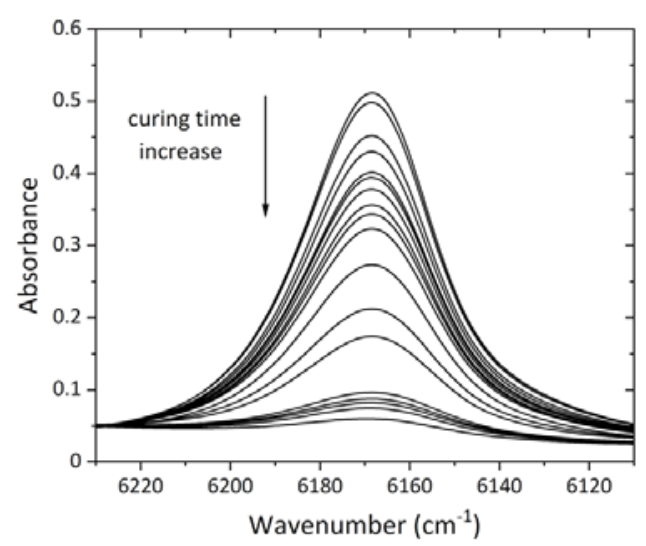

Fig. 1. Evolution of the near IR band assigned to methacrylate $v \mathrm{CH}_{2}=\mathrm{C}<$ groups as a function of UV curing time (0-60 $\mathrm{min}$ ) for a $2 \mathrm{~mm}$-thick sample based on HEMA/ EGDMA/Darocur 1173 (99/0.5/0.5 wt\%). 


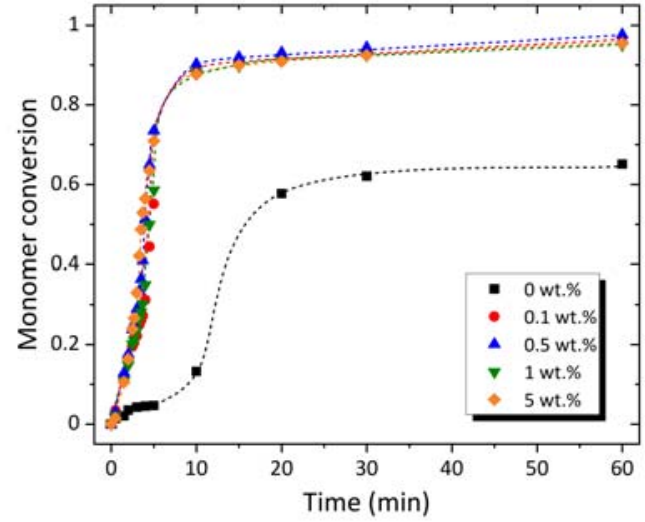

Fig. 2. Monomer conversion as a function of curing time for HEMA/EGDMA/Darocur 1173 at various EGDMA content $(0,0.1,0.5,1$, and $5 \mathrm{wt} \%)$ and constant Darocur 1173 concentration of $0.5 \mathrm{wt} \%$.

taining various amounts of EGDMA $(0,0.1,1$, and $5 \mathrm{wt} \%$ ) were obtained using this method, monomer conversion being calculated from Eq. (4),

$$
X=1-\frac{A_{t}}{A_{0}}
$$

where $A_{t}$ is the measured absorbance at time $t$, and $A_{0}$ is the absorbance before starting irradiation.

The kinetic profile recorded for HEMA polymerization in absence of any cross-linker has the typical sigmoidal shape observed for the bulk polymerization of methyl methacrylate [31], initially with a slow rate and an auto-acceleration stage, well-documented as the Trommsdorff effect [32, 33 ], which develops at about $10 \%$ of monomer conversion, as a consequence of drastic decrease in bimolecular termination rate constant in the viscous medium, and then levels off to reach a final conversion of $60-65 \%$ in the vitrified material (Fig. 2). For monomer blends with EGDMA content as low as $0.1 \mathrm{wt} \%$, polymerization proceeds much faster and exhibits a change to another auto-accelerated regime when the conversion level reaches 30-35\%. Several experiments conducted with EGDMA concentrations between $0.5 \mathrm{wt} \%$ and $5 \mathrm{wt} \%$ showed almost the same profile, with a conversion of $90 \%$ reached within $10 \mathrm{~min}$, and a very slow completion of the reaction between $10 \mathrm{~min}$ and $60 \mathrm{~min}$ of exposure.

From a practical perspective, it was found convenient to produce the xerogels with various contents of cross-linking agent cured by photoirradiation for 15 min.

\section{Photochemical synthesis of neat and SR hydrogels}

UV irradiation (254 $\mathrm{nm}$ ) of concentrated aqueous solutions of HEMA/EGDMA containing hydrogen peroxide as a co-initiator resulted in the formation of permanently cross-linked hydrogels. While this procedure requires high hydrogen peroxide content in the reagent mixture, it is an efficient way of synthesizing poly(HEMA) hydrogels. Gel fractions as a function of exposure dose for various monomer/ aqueous $30 \% \mathrm{H}_{2} \mathrm{O}_{2}$ ratios are shown in Fig. 3.

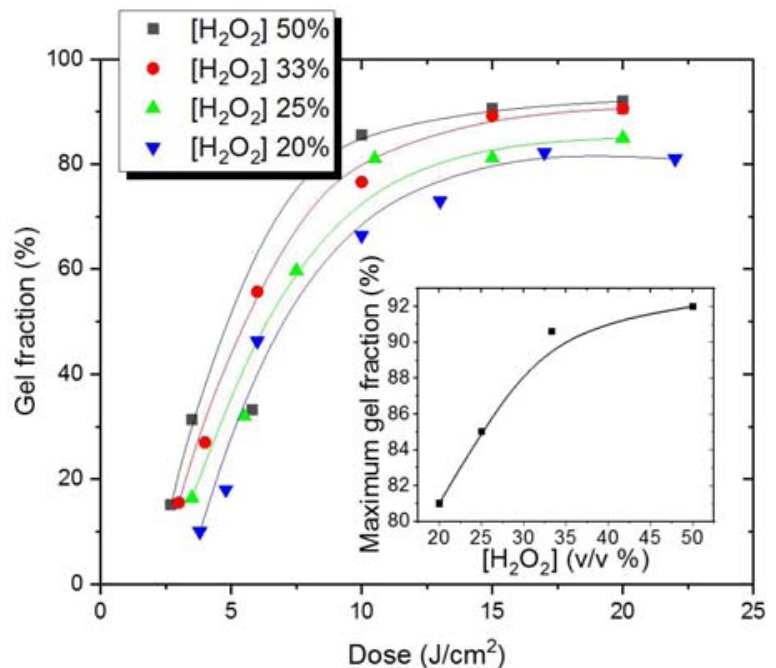

Fig. 3. Gel fraction as a function of exposure dose in synthesizing poly(HEMA) hydrogels by UV irradiation ( $254 \mathrm{~nm}$, irradiance $2.6 \mathrm{~mW} \cdot \mathrm{cm}^{-2}$ ) of concentrated aqueous monomer/cross-linker solution containing hydrogen peroxide. Volume fractions of aqueous $30 \% \mathrm{H}_{2} \mathrm{O}_{2}$ solutions are given in the graph, the remaining fraction being 99/1 v/v HEMA/EGDMA. Inset: maximum gel fraction as a function of hydrogen peroxide content (as the volume fraction of aqueous $30 \% \mathrm{H}_{2} \mathrm{O}_{2}$ solution).

It can be seen that, when this procedure is used, exposure doses necessary to reach considerable gel fraction $(>80 \%)$ are in the range of $10-15 \mathrm{~J} \cdot \mathrm{cm}^{-2}$, which is at least 2-3 times higher than in the case of xerogel synthesis described above. Moreover, the maximum gel content was somewhat lower than for the xerogels. It has been found that both the yield of gel formation and the final gel content depend to some extent on the sample composition. More efficient cross-linking and higher gel fractions were obtained for samples of higher $\mathrm{H}_{2} \mathrm{O}_{2} /$ monomer ratios, albeit these dependencies were not much pronounced ( $11 \%$ increase in gel fraction achieved by more than doubling the peroxide content, see inset in Fig. 3). Another indication of hydrogen peroxide influence on the cross-linking process is the values of gelation doses, $D_{g}$, understood as the minimum exposure doses at which macroscopic gel appears in the system, calculated from data shown in Fig. 3 using the modified Charlesby-Pinner approach [34] (Table 1).

Gelation doses systematically decrease with the increasing $\mathrm{H}_{2} \mathrm{O}_{2}$ content, pointing out to more efficient cross-linking. These results indicate that the initiation process, rather than the subsequent cross-linking polymerization, is the decisive step governing the efficiency of hydrogel formation in this system.

Another parameter resulting from these calculations is the probability ratio of chain breakage to cross-linking, $p_{0} / q_{0}$. This ratio is zero (within the experimental error) for all hydrogen peroxide concentrations save the lowest one, pointing out that degradation of the formed chains and network is negligible except for low hydrogen peroxide content.

The swelling properties of the poly(HEMA) hydrogels obtained by this method depend on UV exposure dose, as is shown in Fig. 4. 


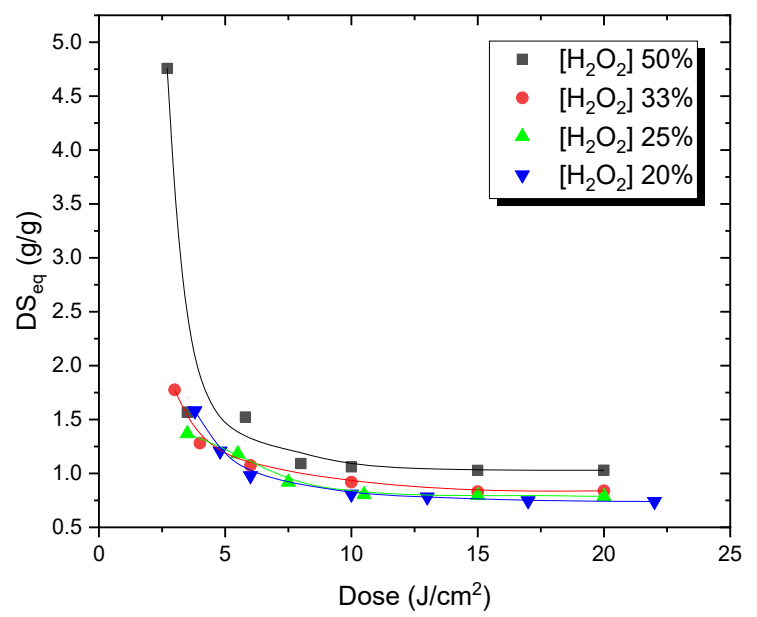

Fig. 4. Equilibrium degree of swelling of poly(HEMA) hydrogels synthesized by UV irradiation $(254 \mathrm{~nm}$, irradiance $2.6 \mathrm{~mW} \cdot \mathrm{cm}^{-2}$ ) of concentrated aqueous monomer/cross-linker solution containing hydrogen peroxide. Volume fractions of aqueous $30 \% \mathrm{H}_{2} \mathrm{O}_{2}$ solutions are given in the graph, the remaining fraction being 99/1 v/v HEMA/ EGDMA. Swelling tests performed in water at RT.

As expected, the cross-link density increases with exposure dose, leading to a pronounced decrease in the equilibrium degree of swelling. At high doses, while monomer and cross-linker are nearly fully converted into a 3D network, the gels can adsorb ca. $0.8-1.2 \mathrm{~g}$ of water per gram of dry gel. While there is no pronounced difference in the swelling properties between the gels synthesized in the presence of 20-33\% of hydrogen peroxide solution (and $67-80 \%$ of monomer/cross-linker mixture), products based on irradiation of samples containing $50 \%$ of $\mathrm{H}_{2} \mathrm{O}_{2}$ solution (and 50\% of HEMA/EGDMA) have somewhat higher tendency to swell. This indicates that solutions irradiated at relatively low monomer and cross-linker concentrations formed somewhat less densely cross-linked networks.

Based on the above-described synthetic procedure, three kinds of stimuli-sensitive hydrogels have been synthesized, where HEMA/EGDMA has been polymerized and cross-linked in the presence of MADQUAT or AA to render $\mathrm{pH}$-responsive properties or $\mathrm{N}$-isopropylacrylamide to yield temperature-sensitive products, respectively. The exposure dose for these samples has been set at $8 \mathrm{~J} \cdot \mathrm{cm}^{-2}$ and the volume fraction of aqueous $30 \%$ hydrogen peroxide was constant at 50\%. Samples contained 45-48.75 vol.\% of HEMA/EGDMA (99:1) and 1.25-5 vol.\% of one of the above-listed monomers (or its $75 \%$ aqueous solution in the case of MADQUAT).

The influence of MADQUAT content on the gel fraction is shown in Table 2 .

Increasing the MADQUAT fraction has a clear negative effect on the efficiency of gel formation. This can be traced down to the positive charge on the monomer, which causes electrostatic repulsion between the growing polymer chains and the monomer, and also to the scavenging of ${ }^{\circ} \mathrm{OH}$ radicals resulting from photolysis of hydrogen peroxide by chloride ions, a very efficient reaction $\left(k=4.3 \times 10^{9} \mathrm{dm}^{3} \cdot \mathrm{mol}^{-1} \cdot \mathrm{s}^{-1}\right.$ [35]). Nevertheless, at MADQUAT concentrations up to $2.5 \mathrm{vol} . \%$ of its $75 \%$ solution, stable gels of

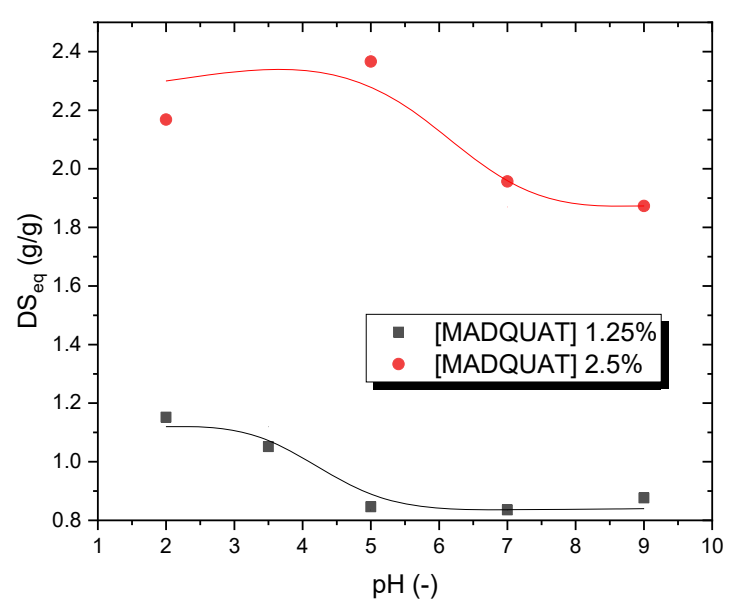

Fig. 5. Equilibrium degree of swelling of poly(HEMA-co-MADQUAT) hydrogels synthesized by UV irradiation (254 nm, irradiance $2.6 \mathrm{~mW} \cdot \mathrm{cm}^{-2}$, exposure dose $8 \mathrm{~J} \cdot \mathrm{cm}^{-2}$ ) of solutions composed of $50 \mathrm{vol} \%$ of aqueous $30 \%$ hydrogen peroxide, $47.5-48.75$ vol.\% of HEMA/EGDMA (99/1) and 1.25-2.5 vol.\% of aqueous 75\% MADQUAT, as a function of $\mathrm{pH}$.

reasonable mechanical properties are obtained. Their behaviour in water at various $\mathrm{pH}$ is shown in Fig. 5 .

In the whole range of tested $\mathrm{pH}$, the equilibrium degree of swelling is significantly higher for the gel synthesized with higher MADQUAT contents. This can be traced down to two effects - lower cross-link density due to less efficient cross-linking polymerization and also higher hydrophilicity of the network due to the higher content of highly hydrophilic MADQUAT. Both synthesized gels show some response to $\mathrm{pH}$, with the transition located in the $\mathrm{pH}$ range of $4-6$.

The method can also be applied for synthesizing hydrogels containing AA. The efficiency of gel formation is in this case significantly higher than for MADQUAT. Interestingly, the addition of $1.25 \%$ of AA to the HEMA/EGDMA solution in water/ $\mathrm{H}_{2} \mathrm{O}_{2}$ seems to increase the gel fraction (Table 3), which might be related to hydrogen bond formation between the growing poly(HEMA) chains and protonated AA, an effect potentially facilitating polymerization. Only when higher amounts of AA are added, some decrease in the cross-linking yield is observed. The obtained gels are strongly sensitive to $\mathrm{pH}$ (Fig. 6).

At low $\mathrm{pH}$, most of the carboxylic groups are protonated. There is no charge along the chain, thus no repulsive forces act between the segments, and also hydroxyl groups of HEMA may form hydrogen bonds with protonated carboxylic groups. Therefore the swelling ability of the gel is moderate. However, at $\mathrm{pH}>5$, deprotonation of carboxylic groups leads to the formation of ionic groups and an increase of linear charge density along the chains. High hydrophilicity and electrostatic repulsion between the charged chain segments lead to strong expansion and swelling. The equilibrium degree of swelling at neutral and high $\mathrm{pH}$ depends on the content of AA in the initial mixture. While for $1.25 \%$ of AA it levels off at ca. $9 \mathrm{~g} \cdot \mathrm{g}^{-1}$, for higher AA content it reaches over $30 \mathrm{~g} \cdot \mathrm{g}^{-1}$ at $\mathrm{pH}$ 9. Such pronounced $\mathrm{pH}$ 


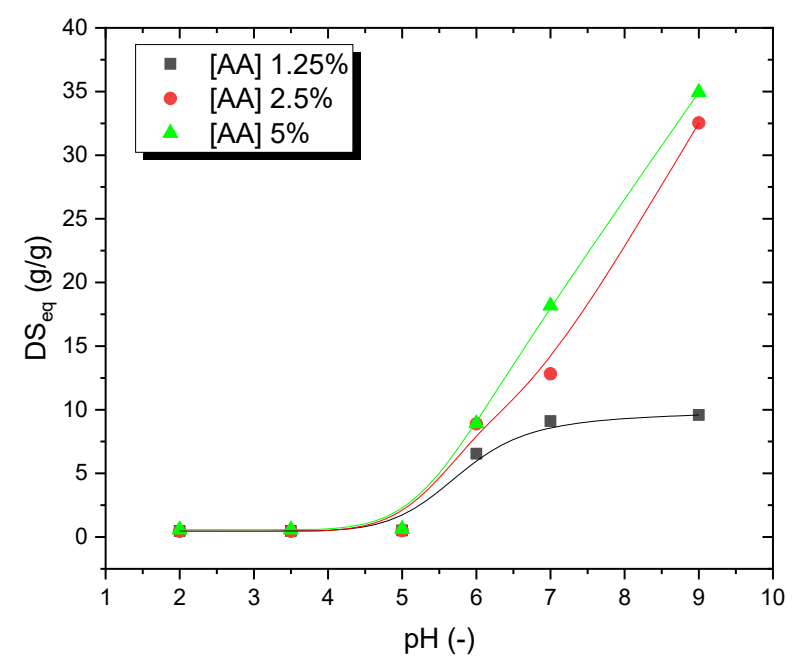

Fig. 6. Equilibrium degree of swelling of poly(HEMA-co-AA) hydrogels synthesized by UV irradiation $(254 \mathrm{~nm}$, irradiance $2.6 \mathrm{~mW} \cdot \mathrm{cm}^{-2}$, exposure dose $8 \mathrm{~J} \cdot \mathrm{cm}^{-2}$ ) of solutions composed of $50 \mathrm{vol} \%$ of aqueous $30 \%$ hydrogen peroxide, 45-48.75 vol.\% of HEMA/EGDMA (99/1) and $1.25-5$ vol. $\%$ of $\mathrm{AA}$, as a function of $\mathrm{pH}$.

effects are known from studies on neat poly(AA) hydrogels [36]. It is expected that the average $\mathrm{p} K_{a}$ of carboxylic groups in the studied copolymer gels is between the values for the low-molecular-weight analog, i.e. propionic acid $\left(\mathrm{p} K_{a}=4.9\right.$ [37]) and for poly(AA) (average $\mathrm{p} K_{a} \approx 6$ [38]). Comparing these values to the data shown in Fig. 6 indicates that in the obtained gels more than half of the carboxylic groups must be dissociated for a strong increase in swelling capacity to be observed.

Gel fractions obtained by UV-irradiation of samples containing $1.25-5$ vol. $\%$ of NIPAm (50 vol.\% of 30\% aqueous hydrogen peroxide, $45-48.75 \mathrm{vol} . \%$ of HEMA/EGDMA (99/1)) are shown in Table 4, while Fig. 7 illustrates equilibrium degree of swelling for NIPAm-containing hydrogels as a function of temperature.

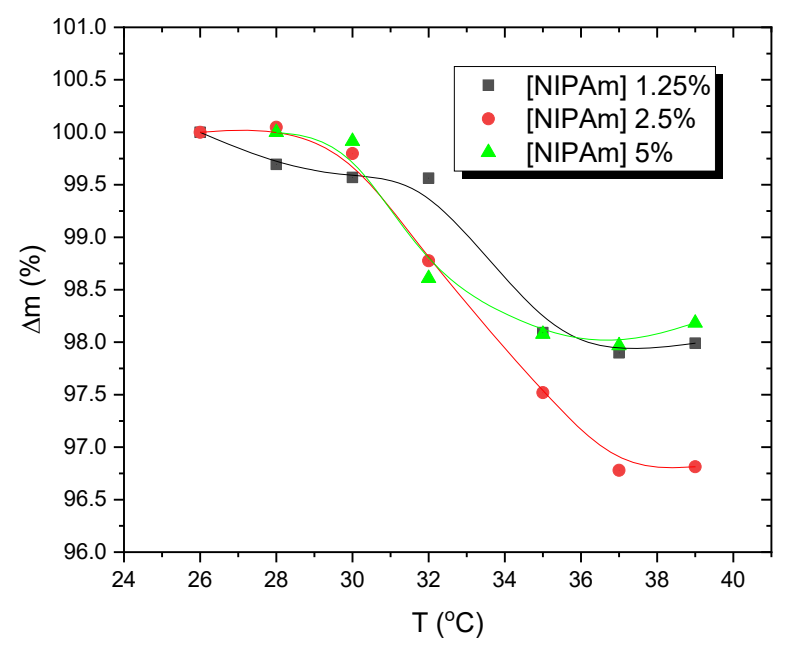

Fig. 7. Weight at equilibrium swelling of poly(HEMA-co-NIPAm) hydrogels synthesized by UV irradiation (254 $\mathrm{nm}$, irradiance $2.6 \mathrm{~mW} \cdot \mathrm{cm}^{-2}$, absorbed dose $8 \mathrm{~J} \cdot \mathrm{cm}^{-2}$ ) of solutions composed of $50 \mathrm{vol} . \%$ of aqueous 30\% hydrogen peroxide, 45-48.75 vol.\% of HEMA/EGDMA (99/1) and $1.25-5 \mathrm{vol} . \%$ of NIPAm, as a function of temperature, normalized to the weight at equilibrium swelling at $26.0^{\circ} \mathrm{C}$.
While NIPAm content in the studied systems was relatively low, the products do exhibit some responsiveness to temperature. The observed mild but clear changes occur at a transition temperature of ca. $32-34^{\circ} \mathrm{C}$, which agrees well with the LCST of poly (NIPAm) in water [39]. Interestingly, the highest amplitude of changes in equilibrium degree of swelling was observed for hydrogels based on samples of $2.5 \mathrm{vol} . \%$ of NIPAm, i.e., the medium NIPAm content within the used range.

\section{Swelling properties of xerogels modified by ionizing radiation}

Polymers exposed to ionizing irradiation generally undergo competing cross-linking and chain scission (degradation) processes, yielding final properties of the material that depend critically on the balance between these two main reaction pathways. Methacrylate polymers, particularly PMMA, are known to be sensitive to the direct effect of ionizing radiation and primarily degrade through main chain scission $[40,41]$. However, due to the presence of functional side-groups, particularly when water is present inside the polymer matrix (i.e. hydrogels), one can expect that the products of water radiolysis, namely $\mathrm{e}_{\mathrm{aq}}^{-}$and strongly oxidizing hydroxyl radicals $\cdot \mathrm{OH}$, may promote reactions of hydroxyethyl ester lateral chains, which may result in intrachain bridges and intermolecular cross-links.

Therefore, to investigate the radiation-induced changes occurring in the water-swollen poly(HEMA) network, hydrogel disks were exposed to $10 \mathrm{MeV}$ EB irradiation at doses varied between $5 \mathrm{kGy}$ and $100 \mathrm{kGy}$. Before EB irradiation, the disks were equilibrated in pure water and dried of total three times to eliminate the non-reacted compounds during photo-polymerization from the xerogels. After irradiation, the same washing protocol has been applied to leach out the products of polymer radiolysis. All disks have been dried to constant weight before swelling measurements. To assess the radiation-induced changes in our system, the diffusion coefficients were calculated following the formalism of the second Fick's law, considering an unsteady one-dimensional diffusion under isothermal conditions. For a short-time approximation, a solution of Fick's second law for a plane sheet of thickness $l$ can be expressed by Eq. (5),

$$
\frac{m_{t}}{m_{\infty}}=\frac{4}{l}\left(\frac{D t}{\pi}\right)^{1 / 2}
$$

where $m_{t}$ is the mass of the swollen sample at time $t, m_{\infty}$ is the equilibrium mass, and $l$ is the thickness of the studied disk. From the latter, for Fickian diffusion, one can express diffusion coefficient $D$ which is proportional to the square of the slope, $\beta$, according to Eq. (6) [42].

$$
D=\frac{\pi l^{2} \beta^{2}}{16}
$$

Figure 8 depicts swelling kinetic profiles of poly(HEMA) hydrogels irradiated at various doses as compared to non-irradiated ones which follow 


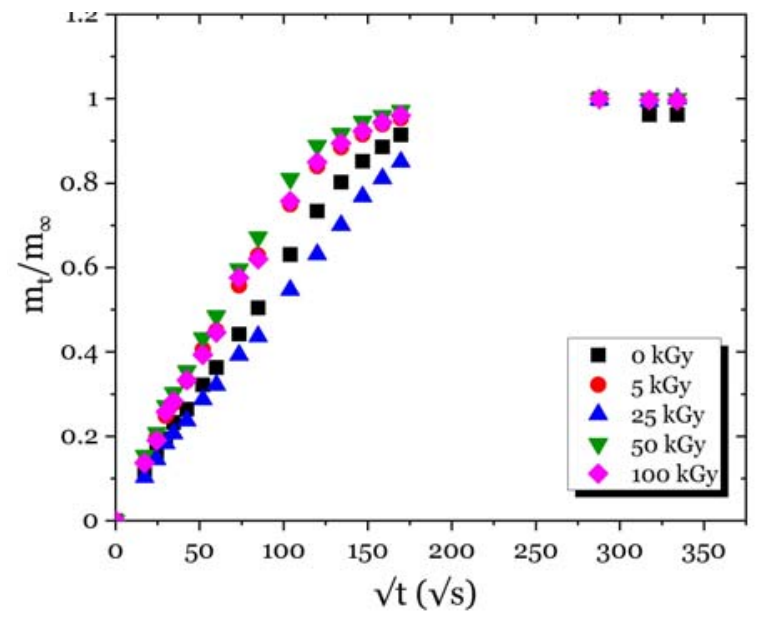

Fig. 8. Effect of irradiation dose (0-100 kGy) applied to the water-swollen hydrogels on their swelling kinetic profiles of the corresponding dried xerogels soaked in water at $30^{\circ} \mathrm{C}$.

Fickian type diffusion $(n=0.5)$. There was only a slight variation of the diffusion coefficient with dose observed $-D$ increases from 1.40 to $1.75 \times$ $10^{-11} \mathrm{~m}^{2} \cdot \mathrm{s}^{-1}$ as the dose was increased from 0 to $100 \mathrm{kGy}$, respectively. In contrast with this increase of the diffusion coefficient for irradiated poly(HEMA) hydrogels, the weight loss measured after extensive desorption of the soluble components in water was found to be somewhat smaller than that of polymer EB-irradiated in the dry state $(2.90 \%$ and $6.2 \%$ at $100 \mathrm{kGy}$, respectively). Furthermore, the equilibrium degree of swelling of these gels remained virtually independent on the dose.

It can be suggested therefore that EB irradiation $(<100 \mathrm{kGy})$ seems to induce cross-linking in hydrogels while xerogels primarily tend to degrade with a higher weight loss supported by larger amounts of extractables. At the same time, it has little effect on the polymer network. It is worth mentioning that as far as bulk photopolymerization is used, network formation under non-equilibrium conditions can also result in uncontrolled defects within the network, hence inducing some variability in the obtained results.

DMA is another sensitive technique for investigating the changes in the dynamics of polymer chains in a network over large temperature ranges. Figure 9 shows the very small evolution of the dissipation factor $\tan \delta$ recorded by thermomechanical analysis of poly(HEMA) networks irradiated in the equilibrium water-swollen state. The glass transition temperature $T_{g}$ seems to vary very slightly, by only a few degrees (from $124.4^{\circ} \mathrm{C}$ before irradiation to $126.1^{\circ} \mathrm{C}$ after $50 \mathrm{kGy}$ ), while the tan $\delta_{\max }$ value decreases smoothly from 0.92 to 0.86 in the same dose interval. These two observations can be interpreted by a limited loss in mobility for the macromolecular chains upon irradiation, as a consequence of a reduction of free volume and an increase in cross-link density with dose.

These results obtained by assessing transport and thermophysical properties of irradiated poly(HEMA) networks neither reveal a strong trend

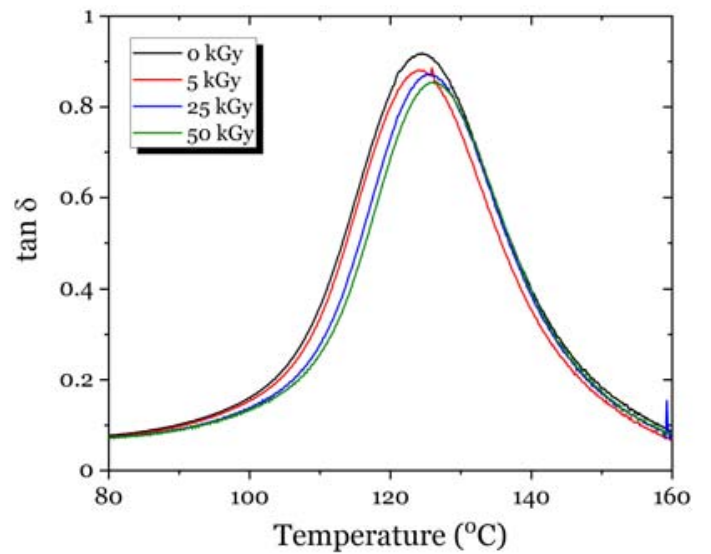

Fig. 9. Plots of thermomechanical dissipation factor tan $\delta$ against temperature in DMA measured for poly(HEMA) hydrogels EB irradiated at 5-100 kGy. Measurement parameters: $1 \mathrm{~Hz}$ frequency and $15 \mu \mathrm{m}$ amplitude in the temperature interval from $30^{\circ} \mathrm{C}$ to $180^{\circ} \mathrm{C}$.

towards chain scission nor a dominant increase in cross-linking density upon EB irradiation of the swollen hydrogels. This suggests that both processes seem to balance each other out. A deeper investigation with quantitative measurements of the effects of radiation on linear poly (HEMA) would allow to ascertain these preliminary conclusions. Concerning our main objective consisting in the formation of AuNPs within the hydrogels, the limited effects on the poly(HEMA) matrix observed at doses below 15-20 kGy provides an interesting processing window for the radiolytic reduction of $\mathrm{Au}$ (III) ions with minimal impact on the properties of the host polymer.

\section{In-situ radiolytic reduction of $\mathrm{Au}(\mathrm{III})$ salts within swollen hydrogels}

To produce nanocomposites, poly(HEMA) disks were equilibrated in $1 \mathrm{mM} \mathrm{Au}$ (III) aqueous solutions, sealed in plastic bags (under air), and stored in dark before EB irradiation. No radical scavenger was used at this stage of the study. Preliminary experiments showed that the xerogel samples, when used as prepared by photopolymerization, were able to form AuNPs upon $\mathrm{Au}$ (III) sorption, likely due to the presence of occluded reducing species within the vitrified matrix. This undesirable effect was suppressed by pre-swelling the material in water and drying which may result either in relaxation and quenching of trapped reactive species or desorption of reductive compounds.

After pre-washing, $\mathrm{Au}$ (III) loaded hydrogel disks were found chemically inert concerning the guest ions and were suitable for studying the effect of an EB treatment at doses varied from $5 \mathrm{kGy}$ to $25 \mathrm{kGy}$. Upon irradiation, the initially pale yellow-coloured disks turned dark pink, exhibiting an absorption band at ca. $550 \mathrm{~nm}$ which is a characteristic feature of surface plasmon resonance (SPR) of AuNPs.

First, hydrogels soaked in $1 \mathrm{mM} \mathrm{Au}$ (III) were EB irradiated at doses of 0-25 kGy. A slight blue shifting and narrowing of the SPR band by increasing the 


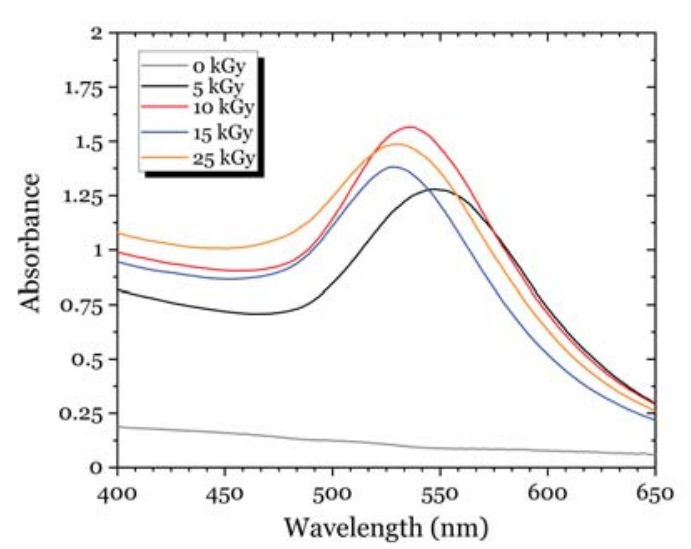

Fig. 10. Effect of EB dose on the visible absorption spectrum of poly(HEMA)-AuNPs composite disks (1 mm-thick, soaked in $1 \mathrm{mM} \mathrm{Au}(\mathrm{III}))$.

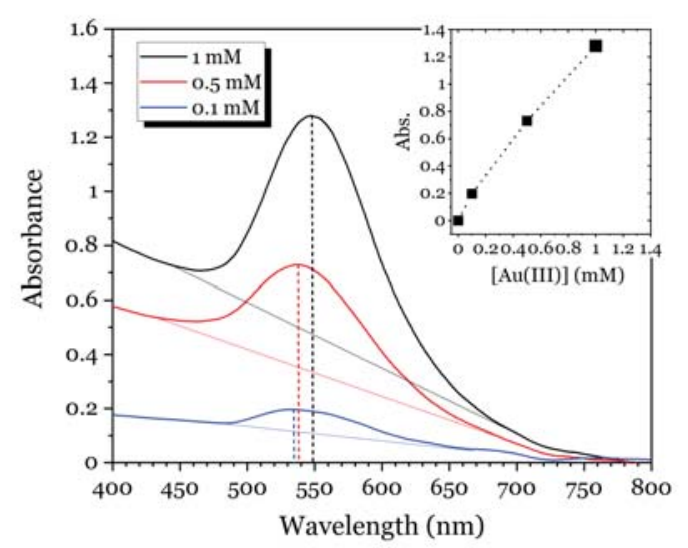

Fig. 11. Radiolytic formation of AuNPs within poly(HEMA) matrix upon EB irradiation of $1 \mathrm{mM}, 0.5 \mathrm{mM}$, and $0.1 \mathrm{mM}$ $\mathrm{Au}$ (III) loaded hydrogels at $5 \mathrm{kGy}$. Inset: Absorbance as a function of $\mathrm{Au}(\mathrm{III})$ concentration.

absorbed dose of radiation (Fig. 10) were observed, indicating a smaller NP size.

Figure 11 depicts UV-vis spectra of poly(HEMA)-AuNPs hydrogel composites equilibrated in $\mathrm{Au}$ (III) aqueous solutions of various concentrations before irradiation. As seen from the inset in Fig. 11, the SPR band is increasing monotonically and almost proportionally with increasing of $\mathrm{Au}$ (III) concentration, confirming the fact that a $5 \mathrm{kGy}$ dose might not be sufficient whilst a $10 \mathrm{kGy}$ treatment would completely reduce absorbed gold ions.

Figure 12 illustrates the influence of EGDMA content $(0.5,1,2$, and $5 \mathrm{wt} \%)$ on the SPR absorption band of poly(HEMA)-AuNPs composites. The resonance band is shifted from $540 \mathrm{~nm}$ to $531 \mathrm{~nm}$ as the EGDMA content is increased, suggesting the formation of smaller particles with a narrower size distribution. Assuming that the poly(HEMA) networks have a uniform structure, increasing EGDMA concentration results in a higher cross-linking density, with a decrease in the elastic properties of the poly(HEMA) segments. This would expectedly affect the diffusion of reactive species and limit the growth of the metal nanoparticles.

Two different approaches were explored to synthesize AuNPs in a limited area, either by direct $\mathrm{Au}(\mathrm{III})$ reduction within the matrix at various

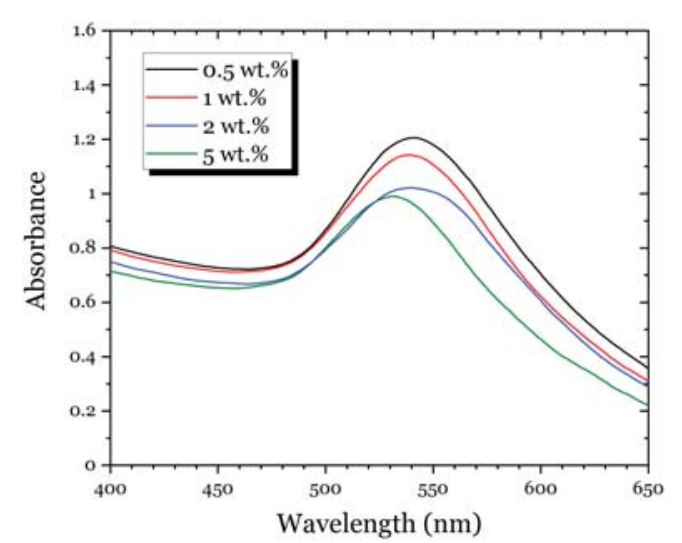

Fig. 12. Radiolytic formation of AuNPs within poly(HEMA) matrix upon EB irradiation of $1 \mathrm{mM} \mathrm{Au}$ (III) loaded hydrogels at $5 \mathrm{kGy}$ with various EGDMA content.

doses or by pre-irradiation of dry or water-swollen disks followed by soaking in $\mathrm{Au}$ (III) solutions. To test the two approaches, lead masks were used to spatially control the irradiated areas in samples exposed to $10 \mathrm{MeV}$ EB at $5 \mathrm{kGy}$. The typical colour change to purple-red assigned to the presence of AuNPs was precisely localized in irradiated areas of $\mathrm{Au}$ (III)-swollen hydrogels and not around (Fig. 13a). Furthermore, pre-irradiation of water-swollen disks and subsequent soaking in $\mathrm{Au}$ (III) solution resulted in a well-defined coloured spot, yet much smaller in intensity (Fig. 13b). To improve the latter approach, one needs to characterize and quantify the long-lived polymeric species responsible for $\mathrm{Au}$ (III) reduction. Based on these results, radiolytic post-modification of 2D and 3D poly(HEMA)-based patterns are envisioned as a promising fabrication method to generate nanocomposites with unique optical and sensing properties.

Radiation-induced formation of gold nanoparticles has also been performed in the poly(HEMA-MADQUAT) gels. Hydrogels obtained by UV irradiation $\left(254 \mathrm{~nm}\right.$, irradiance $2.6 \mathrm{~mW} \cdot \mathrm{cm}^{-2}$, exposure dose $8 \mathrm{~J} \cdot \mathrm{cm}^{-2}$ ) of a solution composed of $50 \mathrm{vol} . \%$ of aqueous 30\% hydrogen peroxide, $47.5 \mathrm{vol} . \%$ of HEMA/EGDMA (99/1) and 2.5 vol.\% of aqueous $75 \%$ MADQUAT, after careful washing and swelling in water for two weeks, have been soaked in aqueous $1 \mathrm{mM} \mathrm{Au}$ (III) solutions of $\mathrm{pH} 2$ and $\mathrm{pH} 7$ for $2 \mathrm{~h}$. Subsequently, they were surface-dried to remove excess liquid, placed in Petri dishes, and irradiated with the access of air by a beam of $6 \mathrm{MeV}$ electrons from a linear accelerator with doses up to $5 \mathrm{kGy}$.

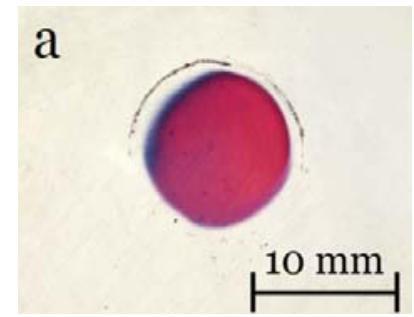

b

Fig. 13. Formation of AuNPs in a limited area exposed to EB of $5 \mathrm{kGy}$ within poly(HEMA) disks (a) swollen in $1 \mathrm{mM} \mathrm{Au}$ (III) before irradiation and (b) post-swollen in $1 \mathrm{mM} \mathrm{Au}$ (III). 
The formation of AuNPs is evidenced by the formation of distinct violet colour, especially in samples irradiated at $\mathrm{pH} 7$ (Fig. 14). Soaking the composite gel in water for $24 \mathrm{~h}$ does not lead to any noticeable leaching of AuNPs from the gel matrix.

The apparent lack of AuNPs formation at $2 \mathrm{kGy}$ is most probably caused by the oxygen content within the gels. The reducing species formed upon irradiation, $\mathrm{e}_{\mathrm{aq}}^{-}$and $\mathrm{H}^{-}$, had been initially strongly scavenged by oxygen until its concentration dropped to the level where the competing reactions of these transients, i.e., reduction of $\mathrm{Au}$ (III), started to dominate, yielding gold nanoparticles. The latter process is expected to be the main reaction channel for nanoparticle formation in our system, while we do not exclude some contribution of the $\alpha$-hydroxyalkyl radicals formed by ${ }^{\circ} \mathrm{OH}$ attack on the HEMA-based

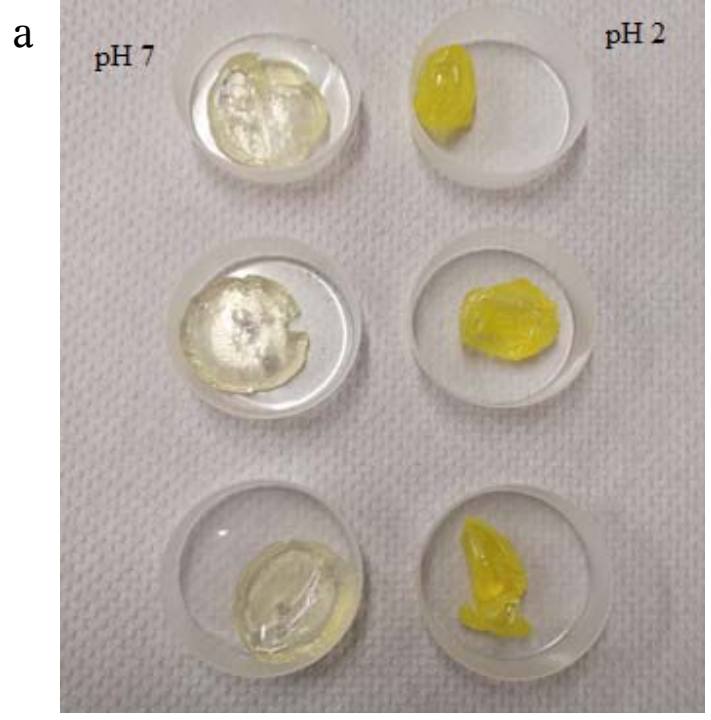

b

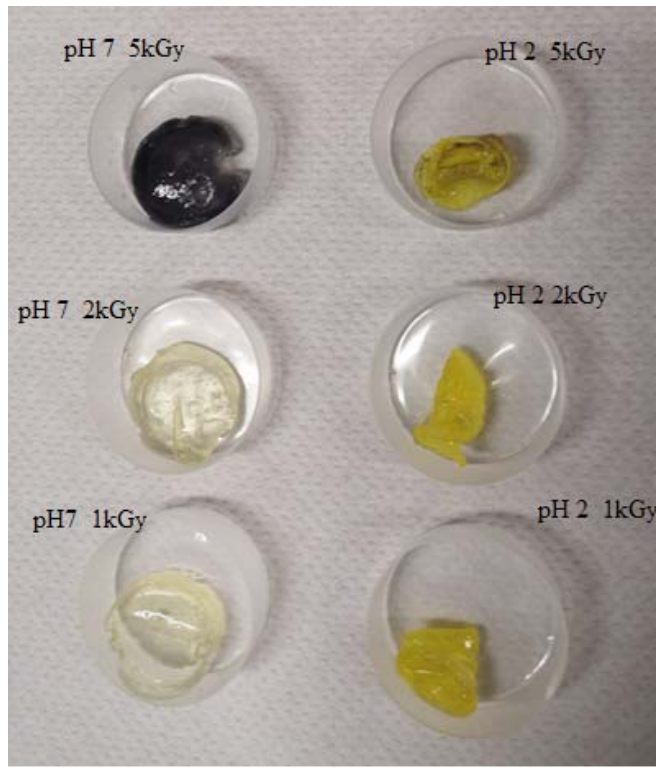

Fig. 14. Poly(HEMA-co-MADQUAT) hydrogels synthesized by UV irradiation $\left(254 \mathrm{~nm}\right.$, irradiance $2.6 \mathrm{~mW} \cdot \mathrm{cm}^{-2}$, exposure dose $8 \mathrm{~J} \cdot \mathrm{cm}^{-2}$ ) of a solution composed of $50 \mathrm{vol} . \%$ of aqueous $30 \%$ hydrogen peroxide, $47.5 \mathrm{vol} \%$ of HEMA/ EGDMA (99/1) and 2.5 vol.\% of aqueous $75 \%$ MADQUAT, (a) non-irradiated and (b) irradiated by EB at various doses after having been soaked in $1 \mathrm{mM} \mathrm{Au}(\mathrm{III})$ solutions of pH 2 and pH 7. network. Radicals of this structure are known to be of reducing character, but their yield in our system and their reaction rate constant with $\mathrm{Au}(\mathrm{III})$ is expected to be much lower than corresponding values for $\mathrm{e}^{-}$aq and $\mathrm{H}^{\circ}$.

While there can be several reasons for the apparent lower yield of AuNPs at pH 2 when compared to $\mathrm{pH} 7$, one of them is the expected difference in reaction rate constant towards $\mathrm{Au}$ (III) between $\mathrm{e}_{\mathrm{aq}}^{-}$ (dominating at $\mathrm{pH} 7$ ) and $\mathrm{H}^{\cdot}$ (dominating at $\mathrm{pH} 2$ ). Such differences have been clearly demonstrated in the case of $\operatorname{Ag}(\mathrm{I})$ reduction, where the rate constant of $\mathrm{e}_{\mathrm{aq}}^{-}$is over threefold higher than that of $\mathrm{H}^{\cdot}$ [35]. In the case of chloroaurate, $k=5.7 \times 10^{9} \mathrm{dm}^{3} \cdot \mathrm{mol}^{-1} \cdot \mathrm{s}^{-1}$ has been determined for reduction by $\mathrm{H}^{*}$ [35], while there are data for the solvated electron in 2-propanol indicating that its reaction with chloroaurate is much faster, at $k=2.6 \times 10^{10} \mathrm{dm}^{3} \cdot \mathrm{mol}^{-1} \cdot \mathrm{s}^{-1}$ [43]. This difference may be of particular importance when these reactions have to compete with $\mathrm{e}_{\mathrm{aq}}^{-}$and $\mathrm{H}^{\bullet}$ scavenging by oxygen.

\section{Conclusion}

Well-defined PHEMA-based networks can be synthesized and used as uniform substrates for in situ formation of patterned AuNP-containing nanocomposites. The cross-link density was evidenced as a key factor influencing the dimensions and the overall concentration of AuNPs produced by EB-irradiation at $10 \mathrm{kGy}$ of poly(HEMA) hydrogels swollen with $1 \mathrm{mM}$ aqueous $\mathrm{Au}$ (III) solutions.

pH-responsive gels can be obtained by a similar synthetic procedure, using MADQUAT or AA as an ionic co-monomer. Furthermore, temperature-sensitive hydrogels can be obtained in this way by copolymerizing HEMA with NIPAm.

This study stresses the lack of knowledge on the impact of radiation treatment on PHEMA and PHEMA-based networks, in terms of the relative trend for scission and cross-linking, amount of extractables, nature of intermediates, and long-lived reactive species. The precise effects, as well as the nature of long-lived intermediates with potential reductive power towards $\mathrm{Au}(\mathrm{III})$ ions, need to be explored in more detail.

The patterned, stimuli-sensitive nanocomposite hydrogels may become a new class of interesting multifunctional materials for electronics, optics, and medicine.

In that perspective, ongoing studies and future developments are currently in progress to gain better control on the conversion of metal salts present in hydrogels into AuNPs of specific size and spatial distribution. Detailed investigation on the nature and amount of remaining active species in the cured xerogels, as well as on the processing conditions by pre-irradiation or simultaneous treatment on the efficiency of reduction reactions should help to go further.

Detailed characterization of the optical properties resulting from the presence of AuNPs in the hydrogels along with their evolution with time, leaching of AuNPs, study of the temperature and 
$\mathrm{pH}$ responsiveness will be helpful for the design of novel patterned nanocomposites with specific functionalities.

Acknowledgments. The authors wish to acknowledge the support of Conseil régional du Grand Est, MENESR, and EU-FEDER Program (CPER Project PlAneT) by funding the MIPPI-4D project. This work has been initiated and is currently supported by the International Atomic Energy Agency in the frame of the Coordinated Research Project F 22070 "Enhancing the beneficial effects of radiation processing in nanotechnology".

\section{ORCID}

X. Coqueret (D http://orcid.org/0000-0002-9645-5506

S. Kadtubowski (D) http://orcid.org/0000-0003-0648-5208

P. Ulański Đi http://orcid.org/0000-0002-4310-3574

\section{References}

1. Kelly, K. L., Coronado, E., Zhao, L. L., \& Schatz, G. C. (2003). The optical properties of metal nanoparticles: the influence of size, shape, and dielectric environment. J. Phys. Chem. B, 107(3), 668-677.

2. Daniel, M. C., \& Astruc, D. (2004). Gold nanoparticles: assembly, supramolecular chemistry, quantumsize-related properties, and applications toward biology, catalysis, and nanotechnology. Chem. Rev., 104(1), 293-346.

3. García, M. A. (2011). Surface plasmons in metallic nanoparticles: fundamentals and applications. J. Phys. D-Appl. Phys., 44(28), 283001.

4. Turkevich, J., Stevenson, P. C., \& Hillier, J. (1951). A study of the nucleation and growth processes in the synthesis of colloidal gold. Discus. Faraday Soc., 11, 55-75.

5. Huang, H. H., Yan, F. Q., Kek, Y. M., Chew, C. H., Xu, G. Q., Ji, W., \& Tang, S. H. (1997). Synthesis, characterization, and nonlinear optical properties of copper nanoparticles. Langmuir, 13(2), 172-175.

6. Sato-Berrú, R., Redón, R., Vázquez Olmos, A., \& Saniger, J. M. (2009). Silver nanoparticles synthesized by direct photoreduction of metal salts. Application in surface-enhanced Raman spectroscopy. J. Raman Spectrosc., 40(4), 376-380.

7. Sánchez-Iglesias, A., Pastoriza-Santos, I., Pérez-Juste, J., Rodríguez-González, B., Garcia de Abajo, F. J., \& Liz-Marzán, L. M. (2006). Synthesis and optical properties of gold nanodecahedra with size control. Adv. Mater., 18(19), 2529-2534.

8. Belloni, J., Mostafavi, M., Remita, H., Marignier, J. L., \& Delcourt, M. O. (1998). Radiation-induced synthesis of mono-and multi-metallic clusters and nanocolloids. New J. Chem., 22(11), 1239-1255.

9. Abedini, A., Daud, A. R., Hamid, M. A. A., Othman, N. K., \& Saion, E. (2013). A review on radiationinduced nucleation and growth of colloidal metallic nanoparticles. Nanoscale Res. Lett., 8(1), 474.

10. Henglein, A. (1999). Radiolytic preparation of ultrafine colloidal gold particles in aqueous solution: opti- cal spectrum, controlled growth, and some chemical reactions. Langmuir, 15(20), 6738-6744.

11. Gachard, E., Remita, H., Khatouri, J., Keita, B., Nadjo, L., \& Belloni, J. (1998). Radiation-induced and chemical formation of gold clusters. New J. Chem., 22(11), 1257-1265.

12. Tagawa, S., Hayashi, N., Yoshida, Y., Washio, M., \& Tabata, Y. (1989). Pulse radiolysis studies on liquid alkanes and related polymers. Int. J. Radiat. Appl. Instrum. C-Radiat. Phys. Chem., 34(4), 503-511.

13. Kapoor, S., Lawless, D., Kennepohl, P., Meisel, D., \& Serpone, N. (1994). Reduction and aggregation of silver ions in aqueous gelatin solutions. Langmuir, 10(9), 3018-3022.

14. Goldenberg, L. M., Sakhno, O. V., Smirnova, T. N., Helliwell, P., Chechik, V., \& Stumpe, J. (2008). Holographic composites with gold nanoparticles: nanoparticles promote polymer segregation. Chem. Mat., 20(14), 4619-4627.

15. Pardo Yissar, V., Gabai, R., Shipway, A. N., Bourenko, T., \& Willner, I. (2001). Gold nanoparticle/hydrogel composites with solvent switchable electronic properties. Adv. Mater., 13(17), 1320-1323.

16. Wang, C., Flynn, N. T., \& Langer, R. (2004). Controlled structure and properties of thermoresponsive nanoparticle-hydrogel composites. Adv. Mater., 16(13), 1074-1079.

17. Marić, I., Vujičić, N. Š., Pustak, A., Gotić, M., \& Jurkin, T. (2020). One-step synthesis of poly (ethylene oxide)/gold nanocomposite hydrogels and suspensions using gamma-irradiation. Radiat. Phys. Chem., 170, 108657.

18. Bond, G. C., \& Thompson, D. T. (2000). Goldcatalysed oxidation of carbon monoxide. Gold Bull., 33(2), 41-50.

19. Belloni, J. (2006). Nucleation, growth and properties of nanoclusters studied by radiation chemistry: application to catalysis. Catal. Today, 113(3/4), 141-156.

20. Evanoff Jr, D. D., \& Chumanov, G. (2005). Synthesis and optical properties of silver nanoparticles and arrays. ChemPhysChem, 6(7), 1221-1231.

21. Vô, K. D. N., Kowandy, C., Dupont, L., \& Coqueret, X. (2015). Evidence of chitosan-mediated reduction of $\mathrm{Au}(\mathrm{III})$ to $\mathrm{Au}(0)$ nanoparticles under electron beam by using $\mathrm{OH}$ and $\mathrm{e}_{\mathrm{aq}}^{-}$scavengers. Chem. Commun., 51(19), 4017-4020.

22. Li, T., Park, H. G., \& Choi, S. H. (2007). $\gamma$-Irradiationinduced preparation of $\mathrm{Ag}$ and $\mathrm{Au}$ nanoparticles and their characterizations. Mater. Chem. Phys., 105(2/3), 325-330.

23. Zhu, C. -H., Hai, Z. -B., Cui, C. -H., Li, H. -H., Chen, J. -F., \& Yu, S. -H. (2012). In situ controlled synthesis of thermosensitive poly(N-isopropylacrylamide)/Au nanocomposite hydrogels by gamma radiation for catalytic application. Small, 8(6), 930-936.

24. Kumaraswamy, S., \& Mallaiah, S. H. (2016). Swelling and mechanical properties of radiation crosslinked $\mathrm{Au} / \mathrm{PVA}$ hydrogel nanocomposites. Radiat. Eff. Defects Solids, 171(11/12), 869-878.

25. Kumaraswamy, S., Srikanth, L. P., \& Somashekarappa, H. M. (2020). Swelling and cytocompatibility studies of Au/PVA hydrogel nanocomposites synthesized using gamma irradiation technique. AIP Conf. Proc., 2244, art. no. 070005. 
26. Kumar, M., Varshney, L., \& Francis, S. (2005). Radiolytic formation of Ag clusters in aqueous polyvinyl alcohol solution and hydrogel matrix. Radiat. Phys. Chem., 73(1), 21-27.

27. Henríquez, C. M. G., Guerra, G. D. C. P., Vallejos, M. A. S., de la Fuente, S. D. R., Flores, M. T. U., \& Jimenez, L. M. R. (2014). In situ silver nanoparticle formation embedded into a photopolymerized hydrogel with biocide properties. J. Nanostructure Chem., 4(4), 119-132.

28. Krklješ, A. N., Marinović-Cincović, M. T., KacarevicPopovic, Z. M., \& Nedeljković, J. M. (2007). Radiolytic synthesis and characterization of Ag-PVA nanocomposites. Eur. Polym. J., 43(6), 2171-2176.

29. Krklješ, A., Nedeljković, J. M., \& Kačarević-Popović, Z. M. (2007). Fabrication of Ag-PVA hydrogel nanocomposite by $\gamma$-irradiation. Polymer Bull., 58(1), 271-279.

30. Jovanović, Ž., Krklješ, A., Stojkovska, J., Tomić, S., Obradović, B., Mišković-Stanković, V., \& KačarevićPopović, Z. (2011). Synthesis and characterization of silver/poly(N-vinyl-2-pyrrolidone) hydrogel nanocomposite obtained by in situ radiolytic method. Radiat. Phys. Chem., 80(11), 1208-1215.

31. Schulz, G. V., \& Harborth, G. (1947). The mechanism of the explosive polymerization of methyl methacrylate. Die Makromolekulare Chemie, 1(1), 106-139.

32. Flory, P. J. (1953). Principles of polymer chemistry. Ithaca, NY: Cornell University Press.

33. Campan, R., Cazaux, F., \& Coqueret, X. (2002). Controlled swelling of poly(hydroxyethyl methacrylate) hydrogels by photochemical grafting of hydrophobic acrylates. Macromol. Mater. Eng., 287(12), 924-930.

34. Olejniczak, J., Rosiak, J., \& Charlesby, A. (1991). $\mathrm{Gel} /$ dose curves for polymers undergoing simultaneous crosslinking and scission. Radiat. Phys. Chem., 37(3), 499-504.

35. Buxton, G. V., Greenstock, C. L., Helman, W. P., \& Ross A. B. (1988). Critical review of rate constants for reactions of hydrated electrons, hydrogen atoms and hydroxyl radicals $\left({ }^{\circ} \mathrm{OH} /{ }^{\cdot} \mathrm{O}^{-}\right)$in aqueous solutions. $J$. Phys. Chem. Ref. Data, 17(2), 513-886.

36. Ilavský, M., Fähnrich, J., Nedbal, J., \& Bouchal, K. (1996). Swelling and photoelastic behaviour of ionized hydrogels of poly(acrylic acid). Polymer Bull., 37, 791-798.

37. Serjeant, E. P., \& Dempsey, B. (1979). Ionisation constants of organic acids in aqueous solution. New York: Pergamon Press. (IUPAC Chemical Data Series No. 23).

38. Oosawa, F. (1971). Polyelectrolytes. New York: Marcel Dekker.

39. Schild, H. G., \& Tirrell, D. A. (1990). Microcalorimetric detection of lower critical solution temperatures in aqueous polymer solutions. J. Phys. Chem., 94, 4352-4356.

40. Alexander, P., Charlesby, A., \& Ross, M. (1954). The degradation of solid polymethylmethacrylate by ionizing radiation. Proc. R. Soc. London Ser. A-Math. Phys. Sci., 223(1154), 392-404.

41. Choi, J. O., Moore, J. A., Corelli, J. C., Silverman, J. P., \& Bakhru, H. (1988). Degradation of poly(methyl methacrylate) by deep ultraviolet, X-ray, electron beam, and proton beam irradiations. J. Vac. Sci. Technol. B, 6(6), 2286-2289.

42. Ritger, P. L., \& Peppas, N. A. (1987). A simple equation for description of solute release I. Fickian and non-fickian release from non-swellable devices in the form of slabs, spheres, cylinders or discs. J. Control. Release, 5(1), 23-36.

43. Dey, G. R., El Omar, A. K., Jacob, J. A., Mostafavi, M., \& Belloni, J. (2011). Mechanism of trivalent gold reduction and reactivity of transient divalent and monovalent gold ions studied by gamma and pulse radiolysis. J. Phys.Chem. A, 115, 383-391. 